\title{
Evaluation of Post-Operative Analgesia Using Clonidine as an Adjuvant with Caudal Bupivacaine in Paediatric Patients Posted for Infraumbilical Surgery
}

\author{
Sinjini Agarwal ${ }^{1}$, Neeta Chaudhari Verma ${ }^{2}$, Amol P.S. ${ }^{3}$, Pyarelal $^{4}$, Suzanna Elsa Varghese ${ }^{5}$, Ankita Nigam ${ }^{6}$ \\ 1,2,3, 5, 6 Department of Anaesthesiology, Jawaharlal Nehru Medical College, Wardha, Maharashtra, \\ India. ${ }^{4}$ Axom Group of Anaesthesia, Hyderabad, Andhra Pradesh, India.
}

\section{ABSTRACT}

\section{BACKGROUND}

Caudal epidural block is a highly popular method of administering analgesia to children undergoing infraumbilical surgeries. Addition of clonidine, a centrally acting alpha 2 agonist as an adjuvant to caudal bupivacaine has added advantages of providing prolonged post-operative analgesia and also, thus reducing the number of doses of post-operative rescue analgesics. In this study, we wanted to compare the efficacy and safety of caudally administered clonidine as an adjuvant to bupivacaine.

\section{METHODS}

This was a prospective, comparative interventional study and was conducted in the Department of Anaesthesia at JNMC, Sawangi (Meghe) Wardha in accordance with the guidelines and permission of the institutional ethical review board. The study was carried out with 40 patients in each group randomly allocated using computer generated software, posted for infraumbilical surgeries between the age group 2 years to 7 years, American Society of Anaesthesiologists (ASA) grade I and II. Group B (control group) - Caudal epidural with $0.25 \%$ bupivacaine $1 \mathrm{ml} / \mathrm{kg}+1 \mathrm{ml}$ normal saline. Group C (study group) - Caudal epidural with $0.25 \%$ bupivacaine $1 \mathrm{ml} / \mathrm{kg}$ with clonidine 1 microgram $/ \mathrm{kg}+1 \mathrm{ml}$ normal saline.

\section{RESULTS}

In our study, the mean duration of analgesia i.e. mean time for requirement of first rescue analgesia in group $C$ was $9.9 \pm 1.4$ hours as compared to $4.7 \pm 1.4$ hours in group $\mathrm{B}(\mathrm{P}<0.0001)$. In this study, we used FLACC (face, legs, activity, cry, consolability) pain scale with its 0 - 10 score range for assessing the pain intensity. At FLACC pain score 4 or more, first dose of rescue analgesic was given. This score was reached at 8.8 hours in Group C (mean FLACC score at $3.8 \pm 0.7$ ) and 3.6 hours in Group B (mean FLACC score $3.4 \pm 0.9$ ) with P value $(=0.014$ ) (significant). Group C required significantly lesser number of rescue analgesics in comparison to Group $B$. The number of doses of rescue analgesics required in the Group B were definitely more than that in Group C wherein $62.5 \%$ required 3 doses and $25 \%$ required 4 doses of rescue analgesics. On the other hand, in Group $\mathrm{C}$ the number of patients requiring more than 2 doses of rescue analgesia was $0 \%$ thus proving the efficacy of clonidine in prolonging post-operative analgesia.

\section{CONCLUSIONS}

We concluded that caudally administered clonidine, in a dose of 1 microgram $/ \mathrm{kg}$ as an adjuvant to $0.25 \%$ bupivacaine $1 \mathrm{ml} / \mathrm{kg}$, proved to be efficacious in providing prolonged analgesia both intraoperatively and post-operatively. Also, we observed that this addition, reduced the requirement of post-operative rescue analgesia and its associated side effects.

\section{KEY WORDS}

Caudal Epidural, Infraumbilical Paediatric Surgery, Clonidine, Bupivacaine, Postoperative Analgesia
Corresponding Author: Dr. Neeta Chaudhari Verma, Department of Anaesthesiology, Jawaharlal Nehru Medical College, Wardha, Maharashtra, India. E-mail: neetachaudhary1234@gmail.com

DOI: $10.14260 /$ jemds/2021/614

How to Cite This Article:

Agarwal S, Verma NC, Amol PS, et al. Evaluation of post-operative analgesia using clonidine as an adjuvant with caudal bupivacaine in paediatric patients posted for infraumbilical surgery. J Evolution Med Dent Sci 2021;10(35):3005-3011, DOI: $10.14260 /$ jemds/2021/614

Submission 12-11-2020,

Peer Review 24-07-2021,

Acceptance 30-07-2021,

Published 30-08-2021.

Copyright (C) 2021 Sinjini Agarwal et al. This is an open access article distributed under Creative Commons Attribution License [Attribution 4.0 International (CC BY 4.0)] 


\section{BACKGROUND}

The international association for the study of pain defines pain as "An unpleasant sensory and emotional experience associated with actual or potential tissue damage, or described in terms of such damage." 1 Pain, post-operatively is unavoidable. Pain is one of the most dreaded complications of any surgical process. Surgery is a form of stress to the body leading to stimulation of free nerve endings and specific nociceptors which leads to post-operative pain. ${ }^{2}$ Pain gains significance in children because of the difficulty in differentiating the reason behind their restlessness. This commonly leads to them receiving less or no analgesia for pain relief.

Caudal epidural analgesia is commonly used in surgeries performed on the infra umbilical region and those performed on the lower extremities. Its use along with balanced anaesthesia helps in the reduction of the dosage of the volatile agents intraoperatively as well opioids used for analgesia.

The sympathetic, sensory and motor blockade, all depend upon the volume and concentration of the drug used.

Bupivacaine has been used for paediatric caudal block in different concentrations ranging from $0.125 \%$ to $0.5 \%$. Higher dosage and concentrations, used for lengthening the extent of analgesia can cause intense motor block and even systemic toxicity. These can be avoided by decreasing the volume and dose of the drug by the addition of an adjuvant.

Clonidine, is a highly lipid soluble imidazole derivative found to extend the duration of nerve block when used as an additive to local anaesthetics agent. ${ }^{3}$ It has shown to decrease inhalational anaesthetic and opioid requirement as well as prolongs the blockade period and analgesia period postoperatively, when added as an adjuvant to local anaesthetic agents. ${ }^{4} \alpha 2$ receptors are extensively located in the brain and spinal lamina and have a role in pain modulation. This extensive location is the reason behind their role in providing analgesia and a reduction in the dosage of local anaesthetics. ${ }^{5}$ But, it does show side effects like sedation, hypotension and bradycardia.

The current study was conducted to be familiar with the pain-relieving efficiency and safety of caudal epidural clonidine as an adjuvant to bupivacaine and compare it with plain caudal epidural bupivacaine for post-operative analgesia in paediatric patients posted for infraumbilical surgery under balanced general anaesthesia.

\section{METHODS}

This was a prospective randomized comparative observational study conducted in the Anaesthesiology Department, in AVBRH affiliated to JNMC, Sawangi, Wardha in accord with the guidelines and permission of the institutional ethical review board, over 2 years from August 2018 to October 2020.

All paediatric patients from 1 year to 8 years, belonging to ASA class I-II paediatric patients weighing $8 \mathrm{~kg}$ to $25 \mathrm{~kg}$, undergoing elective infraumbilical surgeries were included in this study.

Patients with known allergy to any of the study drugs, history of developmental delay or mental retardation, known or suspected coagulopathy, with prior infection at the site of the caudal epidural block, congenital abnormalities concerning the lumbar and caudal spinal region or any other neural disorders, any active disease of the central nervous system (CNS), patients on any other medication, likely to have a drug interaction with the study drugs and the patients refused to participate in the study were excluded from the study.

Randomization was done with the help of computergenerated random number table and a total of 80 patients were randomly allocated into 2 groups of 40 each.

Group B (control group) - Caudal epidural with $0.25 \%$ bupivacaine $1 \mathrm{ml} / \mathrm{kg}+1 \mathrm{ml}$ normal saline.

Group C (study group) - Caudal epidural with $0.25 \%$ bupivacaine $1 \mathrm{ml} / \mathrm{kg}$ with clonidine $1 \mu \mathrm{g} / \mathrm{kg}+1 \mathrm{ml}$ normal saline.

Both the solutions were made of equivolume to avoid bias in the study.

All the patients underwent a pre-anaesthetic evaluation a day prior to surgery. Detailed history was elicited \& thorough general and systemic examination was performed. An airway and spine examination to rule out any spine deformity was also done.

Baseline values of heart rate, mean arterial pressure and Sp02 were noted. Investigations like routine blood and urine examinations, bleeding time and clotting time, chest $\mathrm{x}$-ray if needed, human immunodeficiency virus (HIV), HBsAg and hepatitis $\mathrm{C}$ virus (HCV) were done in all patients. Patient's weights were also recorded.

All the parents were informed about the procedures of anaesthesia and surgery and written consent from them was obtained. Parents of all the patients were asked to keep them nil by mouth (NBM) for 6 hours before surgery. Solid foods were limited for 6 hours, milk for 4 - 5 hours and clear fluids for 2 - 3 hours before surgery. ${ }^{5}$

In the pre-operative room itself, an intravenous line was secured and, Inj. glycopyrrolate $0.004 \mathrm{mg} / \mathrm{kg}$ was given to prevent excessive secretions. The patients were sedated using Inj. $0.5 \mathrm{mg} / \mathrm{kg}$ midazolam in the pre-operative room and Inj. ketamine $2 \mathrm{mg} / \mathrm{kg}$ for their co-operation. They were transferred immediately to operation theatre in left lateral position, with 02 support and $\mathrm{SpO} 2$ monitoring along the way to the operation theatre.

After arrival in the operation theatre, Spo2 monitor was attached along with pre oxygenation through Jackson Rees circuit. Other monitors like non-invasive blood pressure (NIBP), electrocardiography (ECG) leads were also attached. Fluids were administered according to Holliday Segar formula. An optimal temperature with the help of a warmer was maintained to keep the patients warm and prevent hypothermia.

Patients were anaesthetized using standard inhalation induction with nitrous oxide and oxygen (50:50), and sevoflurane (43) along with Inj. ketamine and neuromuscular agent Inj. atracurium (41) $0.5 \mathrm{mg} / \mathrm{kg}$ to facilitate endotracheal intubation. After obtaining adequate depth of anaesthesia, patients were intubated using appropriately sized endotracheal tubes. After endotracheal intubation, confirmation of bilateral air entry and securing of the tube, patients were positioned in the "left lateral decubitus position (Sim's lateral position)" for caudal epidural block. 
After turning all the patients to left lateral position, the posterior superior iliac spine (PSIS) was identified and using the line joining the two PSIS as the base of an equilateral triangle, a point was marked in the midline. This was identified as sacral hiatus. Taking all aseptic precautions, a 22-gauge hypodermic needle was introduced perpendicular to the skin and advanced till it hit the sacrum. After hitting the sacrum, it was withdrawn slightly and inclined at 45 degrees and advanced towards the sacral canal until a pop was felt. Confirmation of the epidural space was done with the "whoosh" test on placing the stethoscope over the lumbar spine region and the lack of resistance was encountered by injection of $2-3 \mathrm{ml}$ of air. Further, the fact that there was no subcutaneous swelling or subcutaneous emphysema confirmed the correct placement of the needle. The drug was injected after aspirating the space for blood or cerebrospinal fluid (CSF). The patient was made supine after dressing of the injection site.

Study drugs were prepared by an anaesthesiologist not involved in the study. The patient as well as the attending anaesthesiologist were not aware of the study drug solution.

General anaesthesia was maintained with $\mathrm{O}_{2}, \mathrm{~N}_{2} \mathrm{O}$, sevoflurane and atracurium as muscle relaxant. SpO2, heart rate and mean arterial pressures were recorded before operation (baseline), at induction, immediately after caudal block marked as 0 min and then every 5 min for the first 15 mins and then every 15 mins until the end of the surgery. Hypotension defined as a decrease in mean arterial pressure more than $30 \%$ from the baseline; if occurred was treated with intravenous fluids and Inj. phenylephrine. Similarly, a decrease in heart rate more than $30 \%$ from the baseline was measured as bradycardia and was treated with Inj. atropine $0.01 \mathrm{mg} / \mathrm{kg}$.

After the surgery was over, the patients were observed for extubation criteria. After meeting all the extubation criteria, the neuromuscular blockade due to Inj. atracurium was reversed with Inj. myopyrrolate $0.005 \mathrm{mg} / \mathrm{kg}$. Total duration of surgery was noted. Heart rate, mean arterial pressure and Sp02 were also monitored at an interval of 15 minutes till 60 minutes then every 2 hours for the next 12 hours.

Quality of analgesia, post-operatively, was assessed using the paediatric observational FLACC (face, leg, activity, cry, consolability) pain scale with its $0-10$ score range (annexure 1).

Each study participant's pain intensity was assessed upon arrival in (15 min), then every 15 minutes for first 60 minutes and every 2 hours for the first 12 hour after operation. At any given point, if the FLACC pain scale score was noted, to be 4 or more than 4 , Inj. paracetamol $10 \mathrm{mg} / \mathrm{kg}$ iv was given as rescue analgesia. Total number of doses of rescue analgesics were noted in both the groups at the end of 12 hours. Sedation score was noted using Ramsay sedation scale (annexure 2) at 15 minutes up to 1 hour and then every 2 hours for up to 12 hours after recovery from anaesthesia.

Side effects during the study period like bradycardia (heart rate $<60$ beats/min), hypotension (30 \% of baseline), urinary retention (defined as time to micturition more than 6 hours requiring foley's catheterization), nausea and vomiting were monitored and respiratory depression(defined as SpO2 $<95 \%$; requiring 02 supplementation). ${ }^{6}$ Bradycardia was treated with Inj. atropine, hypotension with Inj. phenylephrine and vomiting was treated with Inj. ondansetron $0.08 \mathrm{mg} / \mathrm{kg}$

\section{Sampling Size \& Technique}

Sample size has been derived using formula:

$\mathrm{n}=\frac{2\left(\mathrm{Z}_{\alpha}+\mathrm{Z}_{1-\beta}\right)^{2} \sigma^{2}}{\Delta^{2}}$

$\mathrm{Z}_{\alpha}=1.96$ (from $\mathrm{z}$ table) at type I error of $5 \%$.

$\mathrm{Z}_{1-\beta}=0.8416$ (from $\mathrm{z}$ table) at $80 \%$ power.

$\sigma=$ Standard deviation from previous study

$\Delta^{2}=$ Effective size

By adding clonidine at extubation, $45 \%$ patients did not require rescue analgesia.

$\mathrm{n}=\frac{2(1.96+0.8416)^{2}(0.72)^{2}}{(0.45)^{2}}$

$=40.6 / \mathrm{arm}$

$\mathrm{n}=40.6$

80 patients for the study were randomly allocated into two groups of 40 patients each. Group B and Group C.

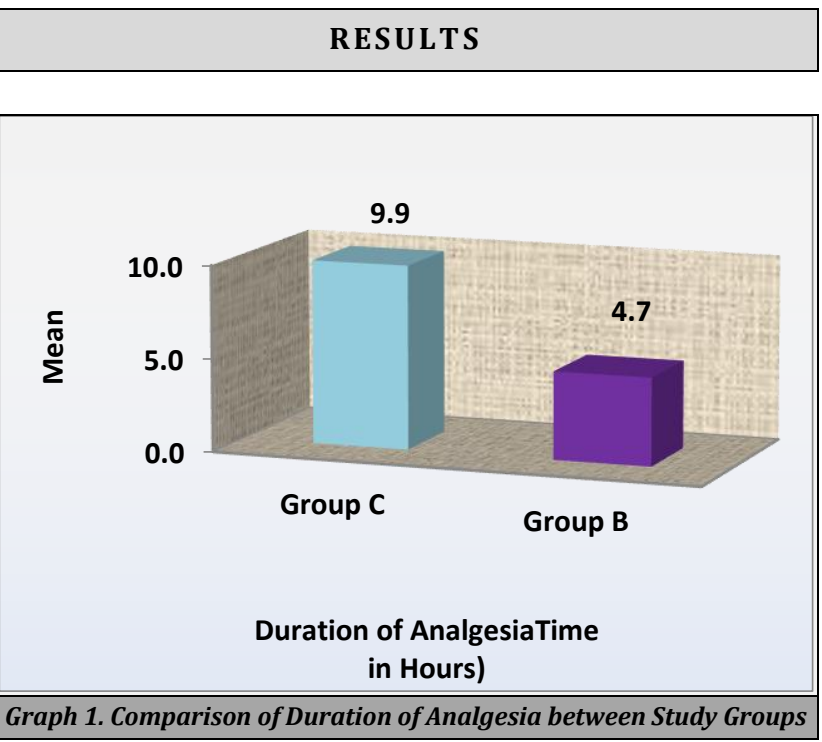

Graph 1 shows the comparison of the mean duration of total analgesia between the 2 study groups.

\begin{tabular}{|c|c|c|c|c|c|c|}
\hline \multirow{2}{*}{$\begin{array}{l}\text { Post-Op FLACC } \\
\text { Score }\end{array}$} & \multicolumn{2}{|c|}{ Group C } & \multicolumn{2}{|c|}{ Group B } & \multirow{2}{*}{$\begin{array}{c}\text { P- } \\
\text { Value }\end{array}$} & \multirow{2}{*}{$\begin{array}{c}\text { Significance } \\
\text { Level }\end{array}$} \\
\hline & Mean & SD ( $( \pm)$ & Mean & SD ( \pm ) & & \\
\hline $15 \mathrm{MIN}$ & 0.0 & 0.2 & 1.0 & 0.6 & $<0.001^{*}$ & $\mathrm{~S}$ \\
\hline 30 MIN & 0.2 & 0.4 & 1.6 & 0.6 & $<0.001^{*}$ & S \\
\hline $45 \mathrm{MIN}$ & 1.0 & 0.2 & 2.1 & 0.6 & $<0.001^{*}$ & S \\
\hline $60 \mathrm{MIN}$ & 1.2 & 0.4 & 2.7 & 0.5 & $<0.001^{*}$ & $\mathrm{~S}$ \\
\hline 2 HOURS & 1.8 & 0.5 & 3.2 & 0.7 & $<0.001 *$ & $\mathrm{~S}$ \\
\hline 4 HOURS & 2.2 & 0.5 & 3.3 & 1.0 & $<0.001^{*}$ & S \\
\hline 6 HOURS & 2.8 & 0.5 & 3.3 & 0.9 & $<0.001^{*}$ & S \\
\hline 8 HOURS & 3.8 & 0.7 & 3.4 & 0.9 & $0.014^{*}$ & $\mathrm{~S}$ \\
\hline 10 HOURS & 3.2 & 0.7 & 3.6 & 1.0 & $0.045^{*}$ & $S$ \\
\hline 12 HOURS & 3.2 & 0.5 & 3.7 & 0.8 & $0.031^{*}$ & $\mathrm{~S}$ \\
\hline \multicolumn{7}{|c|}{ Table 1. Comparison of FLACC Score between the Two Study Groups } \\
\hline
\end{tabular}

Table 1, shows the comparison of the quality of analgesia between the two groups at various time intervals postoperatively.

The patients belonging to Group $C$ had a comparatively lower FLACC score as compared to Group B throughout the study period with the difference being statistically significant throughout the study period until 8 hours. 


\begin{tabular}{|c|c|c|c|c|c|c|}
\hline \multirow{2}{*}{$\begin{array}{l}\text { No. of Doses in } \\
12 \text { Hours }\end{array}$} & \multicolumn{2}{|c|}{ Group C } & \multicolumn{2}{|c|}{ Group B } & \multirow{2}{*}{ P-Value } & \multirow{2}{*}{$\begin{array}{c}\text { Significance } \\
\text { Level }\end{array}$} \\
\hline & $\mathbf{N}$ & $\%$ & $\mathbf{N}$ & $\%$ & & \\
\hline 1 & 33 & 82.5 & 0 & 0 & \multirow{5}{*}{$<0.001^{*}$} & S \\
\hline 2 & 7 & 17.5 & 5 & 12.5 & & \\
\hline 3 & 0 & 0 & 25 & 62.5 & & $S$ \\
\hline 4 & 0 & 0 & 10 & 25 & & $S$ \\
\hline Total & 40 & 100 & 40 & 100 & & $\mathrm{~S}$ \\
\hline \multicolumn{7}{|c|}{$\begin{array}{c}\text { Table 2. Comparison of Total Number of Rescue Analgesic Doses in } 12 \\
\text { Hours between the Two Study Groups }\end{array}$} \\
\hline \multicolumn{7}{|c|}{ (Note: ${ }^{*}$ significant at $5 \%$ level of significance $(p<0.05)$} \\
\hline
\end{tabular}

Table 2, shows the distribution of patients according to the number of doses of rescue analgesia required. This difference was statistically significant with $\mathrm{P}<0.001$.

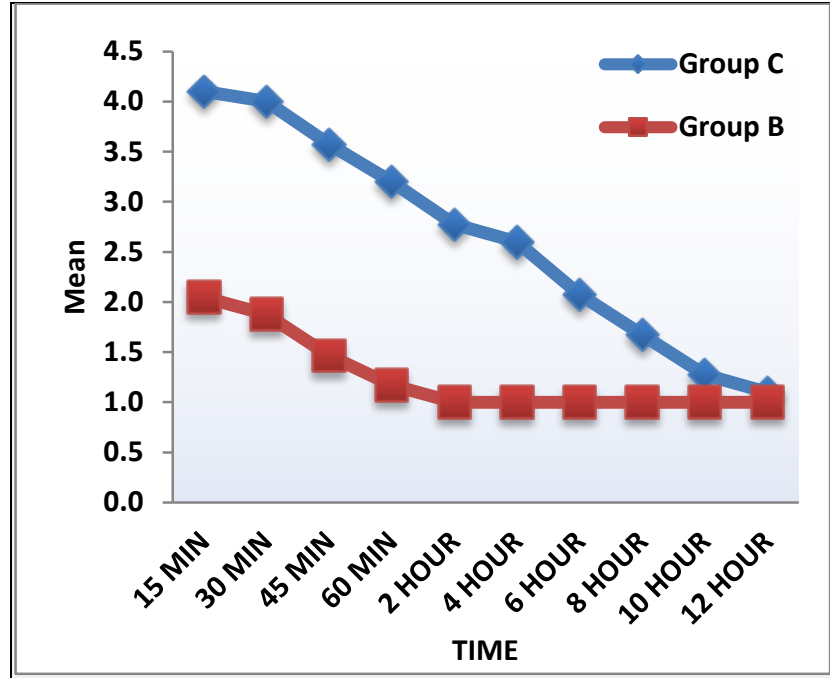

Graph 2. Comparison of Ramsay Sedation Score between Study Groups

Graph 2 shows the distribution of mean modified Ramsay sedation score between the 2 study groups. This value was statistically non-significant suggesting that all the patients in both the groups were wide awake by this time.

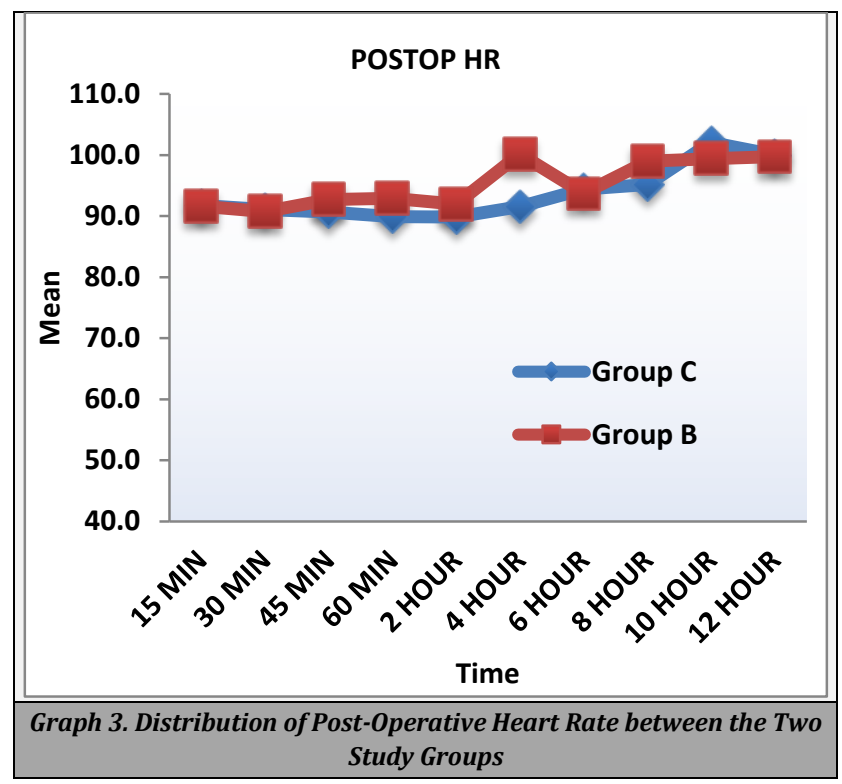

Graph 3 shows the distribution of heart rate between the 2 groups post-operatively. A significant rise in heart rate in group B was noted at the $4^{\text {th }}$ hour which can be attributed to pain (group C $91.6 \pm 11.2$ beats $/$ min and group B 100.2 \pm 6.5 ) and also more than that in group C $(\mathrm{P}<0.0001)$. Similarly, a rise in heart rate in group $C$ was noted at 8 th hour $95.2 \pm 11.7$ and group $\mathrm{B}$ was $99.0 \pm 11.8(\mathrm{P}=0.155)$ and remained increased thereafter.

\begin{tabular}{|c|c|c|c|}
\hline \multirow[t]{2}{*}{ Categories } & \multicolumn{3}{|c|}{ Scoring } \\
\hline & $\mathbf{0}$ & 1 & 2 \\
\hline Face & $\begin{array}{l}\text { Smile or no particular } \\
\text { expression }\end{array}$ & $\begin{array}{l}\text { Occasional grimace or } \\
\text { frown, withdrawn, } \\
\text { disinterested }\end{array}$ & $\begin{array}{l}\text { Frequent to constant } \\
\text { frown, clenched jaw, } \\
\text { quivering chin }\end{array}$ \\
\hline Legs & $\begin{array}{l}\text { Normal position or } \\
\text { relaxed }\end{array}$ & Uneasy, restless, tense & $\begin{array}{l}\text { Kicking, or legs } \\
\text { drawn up }\end{array}$ \\
\hline Activity & $\begin{array}{l}\text { Lying quietly, normal } \\
\text { position, moves easily }\end{array}$ & $\begin{array}{l}\text { Squirming, shifting back } \\
\text { and forth, tense }\end{array}$ & $\begin{array}{l}\text { Arched, rigid, or } \\
\text { jerking }\end{array}$ \\
\hline Cry & $\begin{array}{l}\text { No cry (awake or } \\
\text { asleep) }\end{array}$ & $\begin{array}{l}\text { Moans or whimpers } \\
\text { occasional complaint }\end{array}$ & $\begin{array}{l}\text { Crying steadily } \\
\text { screams or sobs, } \\
\text { frequent complaints }\end{array}$ \\
\hline Consolability & Content, relaxed & $\begin{array}{l}\text { Reassured by occasional } \\
\text { touching, hugging, or } \\
\text { talking to, distractible }\end{array}$ & Difficult to console \\
\hline \multicolumn{4}{|c|}{ Table 3. FLACC Score } \\
\hline
\end{tabular}

\begin{tabular}{|c|}
$0 \quad=$ relaxed and comfortable \\
$1-3=$ mild discomfort \\
$4-6=$ moderate pain \\
$7-10=$ severe discomfort $/$ pain \\
\hline Table 4. Assessment of the Score
\end{tabular}

\begin{tabular}{|cc|}
\hline 1) & Anxious, agitated, restless \\
2) & Co-operative, oriented, tranquil \\
3) & Responds to commands only \\
4 ) & Brisk response to light glabellar tap or loud noise \\
5) & Sluggish response to light glabellar tap or loud noise. \\
6) & No response \\
\hline & Table 5. Modified Ramsay Sedation Scale \\
\hline
\end{tabular}

\section{DISCUSSION}

Post-operative pain is one of the most unpleasant kinds of pain a child may undergo causing anxiety in parents as well. Managing of post-operative pain is of chief prominence in order to evade difficulties of undertreated pain which may influence perioperative outcome undesirably. Regardless of the accessibility of a widespread choice of analgesics, routine management of post-operative pain remains an ongoing challenge. Countless multimodal methods have, therefore, been tried to ameliorate post-operative pain and prolonging its duration of post-operative pain relief. These include parenteral analgesics such as opioids nonsteroidal antiinflammatory drugs (NSAIDs), local site infiltration with local anaesthetics, combining of adjuvants such as opioids and several other agents with local anaesthetic agents for subarachnoid, epidural and caudal epidural blocks, peripheral nerve blocks such as brachial plexus nerve blocks, interpleural, intercostal nerve blocks as well as intraperitoneal routes have also been made use of. But the hunt for a perfect modality is still on. Due to the minimalistic side effects associated with, their use in children, as post-operative analgesic, alpha 2 agonist, as adjuvant, "clonidine" found its way and has created a niche for itself in prolonging the duration of analgesia when administered through caudal epidural block.

The analgesic properties of clonidine administered for the subarachnoid block or caudal epidural block was described in $1984 . .^{7}$ Epidural clonidine proved to be beneficial in adults in providing good analgesia. Therefore, it was further studied and evaluated for its caudal analgesic properties benefitting the paediatric population also.8,9 All the studies found caudal 
clonidine to be markedly increasing the duration of analgesia in the post-operative period. Clonidine when added to local anaesthetic agents behaves like a sedative, analgesic, antianxiety agent, hypnotic, and sympatholytic agent.10,11 Clonidine, an $\alpha-2$ agonist has a faster onset of action with stable cardiovascular parameters making them very effective additives in caudal epidural analgesia. In 1998, Constant et al. ${ }^{12}$ showed that clonidine could be the agent of choice to extend the length of caudal analgesia in children.

Yildiz et al. ${ }^{13}$ analysed the efficiency of clonidine as an additive to bupivacaine. Archna et al. ${ }^{14}$ proved that when clonidine was added to bupivacaine as an additive it enhanced the period of caudal analgesia.

This study was done with the aim to compare the efficacy and safety of $1 \mu \mathrm{g} / \mathrm{kg}$ of clonidine administered caudally with 1 $\mathrm{ml} / \mathrm{kg}$ of $0.25 \%$ bupivacaine in $1 \mathrm{ml}$ of normal saline and that of caudal epidural $1 \mathrm{ml} / \mathrm{kg} 0.25 \%$ bupivacaine in $1 \mathrm{ml}$ of normal saline given at the beginning of surgery for postoperative analgesia in paediatric patients undergoing infraumbilical surgeries under general anaesthesia.

After obtaining approval from the ethics committee and written informed consent from parents of every patient, 80 patients belonging to ASA class I and II posted for elective surgery under general anaesthesia and satisfying all the inclusion criteria were enrolled and they were divided into two groups of 40 patients each.

Group B: Patients who were given $1 \mathrm{ml} / \mathrm{kg}$ of $0.25 \%$ bupivacaine $+1 \mathrm{ml}$ NS via caudal epidural route.

Group C: Patients who were given $1 \mathrm{ml} / \mathrm{kg}$ of $0.25 \%$ bupivacaine $+1 \mu \mathrm{g} / \mathrm{kg}$ of clonidine $+1 \mathrm{ml} \mathrm{NS}$.

\section{Demographic Data}

The patients were comparable with respect to age, gender, weight, and ASA class. The duration of surgery was also comparable within the two groups. ${ }^{15,16}$

\section{Duration of Analgesia}

Patients were monitored from the time of arrival in post anaesthetic care unit (PACU) (15 min) post-operatively till 12 hours. Time of first rescue analgesic requirement was noted. This period was defined as time to first rescue analgesia. It was defined "as the time at which caudal block was administered to the first dose of rescue analgesia from zero hours intraoperatively." Clonidine mimics the actions of descending inhibitory fibers, increases acetylcholine levels in CSF thus causing analgesia.

It was observed that in group $\mathrm{C}$, mean duration of postoperative analgesia was $9.9 \pm 1.4$ hours as compared to $4.7 \pm$ 1.4 hours in group B. The time required for administration of first rescue analgesic was prolonged in clonidine group as compared to plain bupivacaine group.

Our study agrees with another study conducted by Bhatia et al. ${ }^{17}$ concluded that extent of analgesia was time from giving caudal block to giving first dose of rescue analgesic drug or OPS >= 12 or until the child complained of pain. In this study, the children provided with a mixture of $0.25 \%$ bupivacaine with $1-2 \mu \mathrm{g} / \mathrm{kg}$ clonidine had longer period \& quality of analgesia which was delivered by caudal block. The results differ widely depending upon dosage of clonidine used; the duration of analgesia provided range from 6.3 hours to 16.5 hours for $1 \mu \mathrm{g} / \mathrm{kg}$ clonidine to 5.8 hours \& 10.25 hours for 2 $\mu \mathrm{g} / \mathrm{kg}$ clonidine.

Chaudhary et al. ${ }^{18}$ found that the duration of analgesia was significantly prolonged in bupivacaine clonidine group (433.5 $\pm 60.2 \mathrm{~min}$ ) compared to bupivacaine alone group (250.33 \pm $41.4 \mathrm{~min}$ ) in our study.

\section{Number of Rescue Analgesics in the First 12 Hours of Post-Operative Period}

A higher demand of rescue analgesic was observed from patients belonging to bupivacaine group. In group C 33 (82.5 $\%)$ and 7 (17.5\%) patients required first 2 doses of rescue analgesia throughout the study period as compared to patients in group B where most of the patients required $3^{\text {rd }}$ and $4^{\text {th }}$ doses of rescue analgesia. No patients in group $\mathrm{C}$ required $3^{\text {rd }}$ or even $4^{\text {th }}$ dose. There were a greater number of pain free patients in Group C as compared to Group B and the difference between the two groups was statistically significant. $(\mathrm{P}<$ 0.001). The total number of patients asking for rescue analgesics in group B were more as compared to group C. Thus it can be said that clonidine provided better patient contentment in terms of efficient extension of duration of analgesia as compared to bupivacaine alone.19,17,20 J.J. Lee et al. ${ }^{19} 1994$ found that bupivacaine + clonidine group required significantly less supplementary analgesia when compared with the bupivacaine group in complete agreement with the findings of our study. Aruna Parasmeswari et al. ${ }^{16}$ evaluated that clonidine bupivacaine had lower requirements of rescue medications. The results of this study are in accordance with our study. Priolkar et al. ${ }^{20}$ their study indicated that $76 \%$ of patients in the bupivacaine-clonidine group needed only 2 doses of analgesia after surgery in the post-operative period as compared with $96 \%$ of children in the bupivacaine group needing 3 doses or more. The bupivacaine + clonidine group needed considerably lower number of analgesic doses in the postoperative period as compared to the bupivacaine group ( $\mathrm{P}$ $=0.004$ ) which is significant statistically.

\section{Assessment of Quality of Analgesia}

There are various methods of assessing the quality of analgesia in paediatric patients. In this study, we used the FLACC pain scale with its 0 - 10 score range for assessing the pain intensity in both the groups.

It was found that the mean FLACC score in the postoperative period i.e. $15 \mathrm{~min}$ in group $C$ was $0.0 \pm 0.2$ and that in group B was $1.0 \pm 0.6$. It was found that the pain intensity scores were higher as the time from end of the surgery increased. The mean FLACC score at different time intervals till 12 hours of post-operative period was lower in clonidine group with better quality of analgesia as compared to plain bupivacaine group. ${ }^{15,16}$

Thus, we can say that the better quality of analgesia was provided by bupivacaine with the addition of clonidine till 8 hours post-operatively as compared to bupivacaine alone.

The results of our study agree with another study conducted by Aruna Parmeshwari et al. ${ }^{16}$ which also used the FLACC score for pain assessment and found that at the end of 6 hours bupivacaine group had higher FLACC scores than the bupivacaine plus clonidine group. Hanallah pain scale was used by Manjunath et al. ${ }^{21}$ where they compared the clinical 
efficacy of fentanyl and clonidine added to ropivacaine and concluded that groups receiving fentanyl and clonidine with ropivacaine had lower mean HPS scores at the end of 12 hours. They also found that children in clonidine group had better quality and prolonged analgesia as compared to the other groups. Laxmi Ramya et al. ${ }^{22}$ used CHIPPS score to come to the conclusion that clonidine group had lower pain scores at the end of 12 hours as compared to the others. Orpington prognostic score (OPS) score was used by Mehta et al. ${ }^{2}$ where they found that time to first rescue analgesia in plain bupivacaine group was 4 hours and in clonidine group was 11 hours which is significantly higher and completely in sync with our study.

\section{Sedation Score}

The sedative effect of caudal epidural clonidine reflects systemic absorption and by its action on higher centers. It can also be due to cephalad ascent of the drug in the cerebrospinal fluid. Sedation is the desired effect in most of the children which in turn reduces the doses of other sedatives and anxiolytics in the post-operative period. ${ }^{22}$

In our study, we have used the modified Ramsay sedation score. The sedation scores after 8 hours in both the groups were almost similar and statistically not significant. At any point in the study period, the sedation score did not go beyond score 5 . The patients were sedated but arousable throughout. Sharpe p et al..$^{23}$ in their study concluded arousal time was also prolonged in clonidine-bupivacaine group. The sedation score was more with the group given $2 \mu \mathrm{g} / \mathrm{kg}$ of clonidine than that given $1 \mu \mathrm{g} / \mathrm{kg}$ of clonidine. Archna Koul et al. ${ }^{14}$ found the period of sedation was significantly longer in paediatric patients who received clonidine. Our study is comparable to these studies. Nevertheless, from this study, we established that it was difficult to distinguish between sedation and analgesia. We perceived that all patients were sleeping or playful and were at ease. They became agitated only when they experienced pain. The superior pain-relieving influence of clonidine might have been misleading for sedation. Thus, it could not be determined whether the sustained period of sedation was due to, exclusively by the property of clonidine causing sedation or not. Furthermore, the adding clonidine didn't suggestively postpone retrieval from general anaesthesia.

\section{Haemodynamic Changes}

Mean changes in pulse rate, mean arterial pressure and respiratory rate were recorded in every patient starting from 0 hour (after giving caudal blockade) till 12 hours postoperatively. It was observed that there was a decrease in mean pulse rate in patients belonging to both the groups at postoperatively but it was not statistically significant. Other haemodynamic variables like mean blood pressure and mean Sp02 values were comparable and were statistically nonsignificant throughout the study period. The study conducted by Amitha et al. ${ }^{24}$ showed that there was a pronounced decrease in heart rate in the clonidine group which is in concordance with our study.

\section{Post-Operative Complications}

The incidence of post-operative nausea and vomiting was almost similar in both the groups. Only one patient in bupivacaine group developed bradycardia, which was selflimiting. 2 patients in both the groups experienced urinary retention and were managed by foley's catheterization. The incidences, altogether, of side effects were similar in both the groups supported by studies conducted by Archna et al. ${ }^{14}$ and Aruna Parmeshwari et al. ${ }^{16}$

\section{CONCLUSIONS}

Based on the results of our study, we concluded that the addition of $1 \mu \mathrm{g} / \mathrm{kg}$ of clonidine to $1 \mathrm{ml} / \mathrm{kg}$ of $0.25 \%$ bupivacaine is a better alternative to $1 \mathrm{ml} / \mathrm{kg} 0.25 \%$ of plain bupivacaine for providing extended post-operative analgesia in paediatric patients who underwent infraumbilical surgery under general anaesthesia. Clonidine, as an adjunct prolonged the total duration of analgesia, provided a better quality of analgesia and delayed the time to first rescue analgesia after 8 hours with better haemodynamic stability.

Data sharing statement provided by the authors is available with the full text of this article at jemds.com.

Financial or other competing interests: None.

Disclosure forms provided by the authors are available with the full text of this article at jemds.com.

\section{REFERENCES}

[1] International Association for Study of Pain Sub committee on Taxonomy. Pain terms: a list with definitions and notes on usage. Pain 1979;6(3):249.

[2] Mehta S, Makwana J. Comparative study of plain bupivacaine and bupivacaine with clonidine for caudal epidural in paediatric patients. J Med Sci Clin Res 2017;5(6):23230-6.

[3] Pöpping DM, Elia N, Marret E, et al. Clonidine as an adjuvant to local anesthetics for peripheral nerve and plexus blocks: a meta-analysis of randomized trials. Anesthesiology 2009;111(2):406-15.

[4] Keniya VM, Ladi S, Naphade R. Dexmedetomidine attenuates sympathoadrenal response to tracheal intubation and reduces perioperative anaesthetic requirement. Indian J Anaesth 2011;55(4):352-7.

[5] Pankaj K, Rajan PS. Alpha 2 agonists in regional anaesthesia practice: efficient yet safe? Indian J Anaesth 2014;58(6):681-3.

[6] Singh R, Kumar N, Singh P. Randomized controlled trial comparing morphine or clonidine with bupivacaine for caudal analgesia in children undergoing upper abdominal surgery. Br J Anaesth. 2011;106(1):96-100.

[7] Tamsen A, Gordh T. Epidural clonidine produces analgesia. Lancet 1984;2(8396):231-2.

[8] De Mey JC, Strobbe J, Poelaert J, et al. The influence of sufentanil and/or clonidine on the duration of analgesia after a caudal block for hypospadias repair surgery in children. Eur J Anaesthesiol 2000;17(6):379-82.

[9] De Beer DAH, Thomas ML. Caudal additives in children solutions or problems? Br J Anaesth 2003;90(4):487-98.

[10] Vieira AM, Schnaider TB, Brandão ACA, et al. Epidural clonidine or dexmedetomidine for post-cholecystectomy 
analgesia and sedation. Rev Bras Anestesiol 2004;54(4):473-8.

[11] Gabriel JS, Gordin V. Alpha 2 agonists in regional anesthesia and analgesia. Curr Opin Anesthesiol 2001;14(6):751-3.

[12] Constant I, Gall O, Gouyet L, et al. Addition of clonidine or fentanyl to local anaesthetics prolongs the duration of surgical analgesia after single shot caudal block in children. Br J Anaesth 1998;80(3):294-8.

[13] Yildiz TS, Korkmaz F, Solak M, et al. Clonidine addition prolongs the duration of caudal analgesia. Acta Anaesthesiol Scand 2006;50(4):501-4.

[14] Koul A, Pant D, Sood J. Caudal clonidine in day-care paediatric surgery. Indian J Anaesth 2009;53(4):450-4.

[15] El-Hennawy AM, Abd-Elwahab AM, Abd-Elmaksoud AM, et al. Addition of clonidine or dexmedetomidine to bupivacaine prolongs caudal analgesia in children. $\mathrm{Br} \mathrm{J}$ Anaesth 2009;103(2):268-74.

[16] Parameswari A, Dhev AM, Vakamudi M. Efficacy of clonidine as an adjuvant to bupivacaine for caudal analgesia in children undergoing sub-umbilical surgery. Indian J Anaesth 2010;54(5):458-63.

[17] Bhatia U, Chaudhari MJ, Parmar S, et al. A comparative study of caudal bupivacaine and bupivacaine with clonidine for post- operative analgesia in paediatric patients. International J Scientific Research 2013;2(7):385-9.

[18] Kailash C, Chetan S, Manish SC. A comparative study of caudal block with bupivacaine and bupivacaine with clonidine in infraumbilical surgeries in children. Int J Sci
Res 2019;8(6):31-3.

[19] Lee JJ, Rubin AP. Comparison of a bupivacaine-clonidine mixture with plain bupivacaine for caudal analgesia in children. Br J Anaesth 1994;72(3):258-62.

[20] Priolkar S, D'Souza SA. Efficacy and safety of clonidine as an adjuvant to bupivacaine for caudal Analgesia in paediatric infra-umbilical surgeries. J Clin Diagnostic Res 2016;10(9):UC13-6.

[21] Manjunath HG, Sumalatha A. A prospective, randomized, double blind, controlled clinical study of adjuvant effect of fentanyl $(1 \mu \mathrm{g} / \mathrm{kg})$ or clonidine $(2 \mu \mathrm{g} / \mathrm{kg})$ to ropivacaine $0.2 \% 1 \mathrm{ml} / \mathrm{kg}$ for caudal analgesia in children undergoing lower abdominal surgeries. J Evol Med Dent Sci 2014;3(52):12063-72.

[22] Potti LR, Bevinaguddaiah Y, Archana S, et al. Caudal levobupivacaine supplemented with caudal or intravenous clonidine in children undergoing infraumbilical surgery: a randomized, prospective double-blind study. Anesth Essays Res 2017;11(1):211-5.

[23] Sharpe P, Klein JR, Thompson JP, et al. Analgesia for circumcision in a paediatric population: comparison of caudal bupivacaine alone with bupivacaine plus two doses of clonidine. Pediatr Anesth 2001;11(6):695-700.

[24] Amitha S, Vidyadhar M, Thejeswini M, et al. A comparative clinical study between clonidine and tramadol with bupivacaine in caudal epidural for postoperative analgesia in pediatric surgery. Anesth Essays Res 2019;13(2):389-94. 